\title{
Aplikasi Fuzzy Mamdani Untuk Meminimalkan Biaya Produksi Petis
}

\author{
S. Nurmuslimah ${ }^{1)}$, Anggi Yhurinda P.P ${ }^{2)}$, Defri Agatha Mulya ${ }^{3)}$ \\ ${ }^{1}$ Jurusan Sistem Komputer, Fakultas Teknik Elektro dan Teknologi Informasi, \\ Institut Teknologi Adhi Tama Surabaya \\ ${ }^{2}$ Jurusan Sistem Informasi, Fakultas Teknik Elektro dan Teknologi Informasi, \\ Institut Teknologi Adhi Tama Surabaya \\ Email: ${ }^{1}$ puty71naura@gmail.com, ${ }^{2}$ anggi@itats.ac.id
}

\begin{abstract}
Shrimp paste (Petis)is a componentin Indonesian cuisine which is mostly preferred by public. Shrimp paste is made from by products of gravy food processing, usually made of shrimp, fish, or meat which is heated until the liquid becomes thick gravy like densed sauce. Petis Ikan Tuna Super HSR Firm hasa production capacity of 70,000 kg/month then the product increases along with the increase of consumer demand. The company should be able to over come the problem of a surge or drop in demand so that the production process can still run smoothly and the company does not suffer from losses. This research is to create an application that can be used in order to facilitate business owners to monitor the total production so that the production cost can be minimized by using Visual Basic program Studio 6.0. This research is a developed research which applies Mamdani Fuzzy method that takes several stages in its design so that this application can run well, namely the formation of fuzzy sets, the establishment of rules, rule composition determination, and defuzzyfication. By using this system, an accuracy rate of $95.66 \%$ per month can be reached and the production cost can be minimized up to $5.15 \%$ per month.
\end{abstract}

Keywords: Fuzzy Logic, Mamdani Method, Petis

\begin{abstract}
Abstrak
Petis adalah komponen dalam masakan Indonesia yang paling banyak diminati masyarakat. Petis dibuat dari produk sampingan pengolahan makanan berkuah, biasanya dari udang, ikan, atau daging yang dipanasi hingga cairan kuah menjadi kental seperti saus yang lebih padat. UD. Petis Ikan Tuna Super HSR ini mempunyai kapasitas produksi mencapai $70.000 \mathrm{Kg} / \mathrm{bulan}$ kemudian jumlah produk yang dihasilkan semakin meningkat seiring dengan bertambahnya permintaan konsumen. Perusahaan harus bisa mengatasi masalah lonjakan permintaan atau penurunan permintaan sehingga proses produksi tetap berjalan lancar dan perusahaan tidak mengalami kerugian. Penelitian ini bertujuan untuk membuat aplikasi yang bisa digunakan supaya bisa mempermudah pemilik usaha dalam memantau jumlah produksi agar biaya produksi yang dikeluarkan bisa lebih minimal dengan menggunakan program Visual Basic Studio 6.0. Penelitian ini merupakan penelitian pengembangan yang menerapkan metode Fuzzy Mamdani yang dalam perancangannya diperlukan beberapa tahapan agar aplikasi ini bisa berjalan dengan baik, yaitu pembentukan himpunan fuzzy, pembentukan aturan-aturan, penentuan komposisi aturan, dan penegasan (defuzzyfikasi). Dengan menggunakan sistem ini, dapat mencapai tingkat akurasi sebesar 95,66\% per bulan serta dapat meminimalkan biaya produksi sebesar 5,15\% per bulan.
\end{abstract}

Kata kunci: Petis, Logika Fuzzy, Metode Mamdani

\section{Pendahuluan}

Petis adalah komponen dalam masakan Indonesia yang dibuat dari produk sampingan pengolahan makanan berkuah, biasanya dari udang, ikan, atau daging yang dipanasi hingga cairan kuah menjadi kental seperti saus yang lebih padat.

UD. Petis Ikan Tuna Super HSR Galis-Pamekasan adalah salah satu unit dagang yang memproduksi petis dan diambil sebagai studi kasus dari aplikasi fuzzy mamdani untuk meminimalkan biaya produksi, sehingga pendapatan yang dihasilkan meningkat. Unit Dagang ini mempunyai kapasitas produksi mencapai $70.000 \mathrm{~kg} /$ bulan kemudian jumlah produk yang dihasilkan semakin 
meningkat seiring dengan bertambahnya permintaan konsumen. Namun kenyataannya permintaan konsumen tidak selalu tetap, sehingga memaksa perusahaan harus merencanakan kegiatan produksi sebaik-baiknya. Petis adalah komponen dalam masakan Indonesia yang dibuat dari produk sampingan pengolahan makanan berkuah, biasanya dari daging, ikan, atau udang yang dipanasi hingga cairan kuah menjadi kental seperti saus yang lebih padat.

Sistem pendukung keputusan merupakan alat pelengkap bagi mereka yang terlibat dalam proses pengambilan keputusan. Sistem pendukung keputusan mempunyai beberapa sumber intelektual dengan kemampuan dari komputer untuk memperbaiki kualitas keputusan [1]. Di mana sistem pendukung keputusan tidak ditujukan untuk mengganti si pengambil keputusan dalam pembuatan keputusan.

Suatu sistem pendukung keputusan harus memiliki tiga komponen atau sub sistem utama yang menyusunnya, antara lain [2]:

1. Subsistem Basis Data

2. Subsistem Basis Model

3. Subsistem Dialog

Metode fuzzy mamdani merupakan metode yang memetakan suatu input kedalam suatu output tanpa mengabaikan faktor yang ada. Metode ini merupakan kerangka matematis yang digunakan untuk mempresentasikan ketidakpastian, ketidakjelasan, ketidaktepatan, dan kebenaran parsial, sehingga sesuai dengan permasalahan permintaan yang fluktuatif dan jumlah produksi yang tidak pasti [3].

\subsection{Logika Fuzzy}

Logika fuzzy adalah salah satu komponen pembentuk soft computing. Logika fuzzy pertama kali diperkenalkan oleh Prof. Lotfi A. Zadeh pada tahun 1965. Dasar logika fuzzy adalah teori himpunan fuzzy. Pada teori himpunan fuzzy peranan derajat keanggotaan sebagai penentu keberadaan elemen dalam suatu himpunan sangatlah penting. Nilai keanggotaan atau derajat keanggotaan atau membership function menjadi ciri utama dalam penalaran dengan logika fuzzy [3].

\subsection{Alasan Digunakannya Logika Fuzzy}

Adapun beberapa alasan digunakannya logika fuzzy [4] adalah: Konsep logika fuzzy mudah dimengerti. Karena logika fuzzy menggunakan dasar teori himpunan, maka konsep matematis yang mendasari penalaran fuzzy tersebut cukup mudah untuk dimengerti.

1. Logika fuzzy sangat fleksisbel, artinya mampu beradaptasi dengan perubahan-perubahan, dan ketidakpastian yang menyertai permasalahan.

2. Logika fuzzy memiliki toleransi terhadap data yang cukup homogeny, dan kemudian ada beberapa data "eksklusif", maka logika fuzzy memiliki kemampuan untuk menangani data eksklusif tersebut.

3. Logika fuzzy dapat membangun dan mengaplikasikan pengalaman-pengalaman para pakar secara langsung tanpa harus melalui proses pelatihan. Dalam hal ini, sering dikenal dengan istilah fuzzy expert sistem menjadi bagian terpenting.

4. Logika fuzzy dapat bekerjasama dengan teknik-teknik kendali secara konvensional. Hal ini umumnya terjadi pada aplikasi di bidang teknik mesin maupu teknik elektro.

5. Logika fuzzy didasari pada bahasa alami. Logika fuzzy menggunakan bahasa sehari-hari sehingga mudah dimengerti.

\subsection{Metode Mamdani}

Metode Mamdani sering juga dikenal dengan nama metode Max-Min. metode ini diperkenalkan oleh Ebrahim Mamdani pada tahun 1975 [3]. Untuk medapatkan output diperlukan 4 tahapan, antara lain:

1. Pembentukan himpunan fuzzy

Pada Metode Mamdani, baik variabel input maupun variabel output dibagi menjadi satu atau lebih himpunan fuzzy. 
2. Mengaplikasikan fungsi implikasi

Pada Metode Mamdani, fungsi implikasi yang digunakan adalah Min. Secara umum dapat dituliskan:

$\mu_{A \cap B}=\min \left(\mu_{A}[x], \mu_{B}[x]\right)$

3. Komposisi Aturan

Dari hasil aplikasi fungsi implikasi dari tiap aturan, selanjutnya pada metode mamdani menggunakan metode Max untuk melakukan komposisi antar semua aturan. Secara umum dapat dituliskan:

$\mu_{s f}\left[x_{i}\right] \leftarrow \max \left(\mu_{s f}\left[x_{i}\right], \mu_{s f}\left[x_{i}\right]\right)$

Dimana:

$\mu_{s f}\left[x_{i}\right]=$ nilai keanggotaan solusi fuzzy sampai aturan ke-i

$\mu_{s f}\left[x_{i}\right]=$ nilai keanggotaan konsekuensi fuzzy aturan ke-i

4. Penegasan (defuzzyfikasi)

Untuk menentukan hasil defuzzyfikasi pada komposisi aturan Mamdani menggunakan Metode

Centroid (Composite Moment). Pada metode ini, solusi crisp diperoleh dengan cara mengambil titik pusat (COA) daerah fuzzy [4]. Metode penegasan yang akan dipakai disini adalah centroid technique yang digunakan untuk mencari centre of area (COA) dari aggregate sets. Secara umum dirumuskan:

$\operatorname{COA}=\frac{\int_{a}^{b} \mu(x) x d x}{\int_{a}^{b} \mu(x) d x}$

\section{Metode}

Aplikasi Fuzzy Mamdani untuk meminimalkan biaya produksi yaitu aplikasi yang digunakan untuk meminimalkan biaya produksi di UD. Petis Ikan Tuna Super HSR. Tujuan pembuatan aplikasi ini yaitu untuk mempermudah pemilik usaha dalam memantau agar biaya produksi yang dikeluarkan bisa lebih minimal.

Dalam perancangan aplikasi ini diperlukan beberapa tahapan agar aplikasi bisa berjalan dengan baik, yaitu pembentukan himpunan fuzzy, pembentukan aturan-aturan, penentuan komposisi aturan, dan penegasan (defuzzyfikasi) [5].

Variabel yang digunakan dalam sistem ini terdapat 2 variabel yaitu:

a. Variabel input

Variabel input terdiri dari Variabel Permintaan Konsumen, Variabel Persediaan, Variabel

Bahan, dan Variabel Bahan Baku.

b. Variabel output

Variabel output terdiri dari variabel Jumlah produksi dan variabel Biaya.

Berikut ini adalah semesta pembicaraan untuk setiap variabel input dan output:

Tabel 1. Tabel Semesta Pembicaraan untuk setiap variabel

\begin{tabular}{lc}
\hline \multicolumn{1}{c}{ Variabel } & Semesta Pembicaraan \\
\hline Permintaan Konsumen $(\mathrm{kg})$ & {$[2500-4000]$} \\
\hline Persediaan $(\mathrm{kg})$ & {$[2000-3000]$} \\
\hline Bahan $(\mathrm{kg})$ & {$[550-700]$} \\
\hline Bahan Baku $(\mathrm{kg})$ & {$[3050-3200]$} \\
\hline Jumlah Produksi $(\mathrm{kg})$ (variabel output) & {$[2500-4000]$} \\
\hline
\end{tabular}

Pada himpunan fuzzy suatu group yang memiliki suatu kondisi atau keadaan tertentu dalam suatu variabel fuzzy. Berikut ini adalah variabel input dan output yang digunakan, yaitu:

- Variabel input Permintaan Konsumen mempunyai 3 himpunan yaitu sedikit, sedang, dan banyak.

- Variabel input Persediaan mempunyai 3 himpunan yaitu sedikit, sedang, dan banyak.

- Variabel input Bahan mempunyai 3 himpunan yaitu sedikit, sedang, dan banyak

- Variabel input Bahan Baku mempunyai 3 himpunan yaitu sedikit, sedang, dan banyak. 
- Variabel output Jumlah Produksi mempunyai 3 himpunan yaitu berkurang, tetap dan bertambah.

1. Domain

Untuk mengetahui nilai keseluruhan dari semesta pembicaraanya, maka di tentukan pula Domain, berikut adalah domain untuk nilai keseluruhan nilai yang diizinkan dalam semesta pembicaraan:

Tabel 2. Tabel Domain untuk setiap variabel

\begin{tabular}{|c|c|c|}
\hline Variabel & Himpunan & Domain \\
\hline \multirow{3}{*}{ Permintaan Konsumen } & Sedikit & {$[2500-3000]$} \\
\hline & Sedang & {$[3000-3500]$} \\
\hline & Banyak & {$[3500-4000]$} \\
\hline \multirow{3}{*}{ Persediaan } & Sedikit & {$[2000-2330]$} \\
\hline & Sedang & [2330-2660] \\
\hline & Banyak & {$[2660-3000]$} \\
\hline \multirow{3}{*}{ Bahan } & Sedikit & {$[550-600]$} \\
\hline & Sedang & {$[600-650]$} \\
\hline & Banyak & {$[650-700]$} \\
\hline \multirow{3}{*}{ Bahan Baku } & Sedikit & [3050-3100] \\
\hline & Sedang & [3100 - 3150] \\
\hline & Banyak & [3150-3200] \\
\hline \multirow{3}{*}{$\begin{array}{l}\text { Jumlah Produksi } \\
\text { (variabel output) }\end{array}$} & Berkurang & {$[2500-3000]$} \\
\hline & Tetap & {$[3000-3500]$} \\
\hline & Bertambah & {$[3500-4000]$} \\
\hline
\end{tabular}

\section{Fungsi Keanggotaan}

Fungsi keanggotaan merupakan suatu grup yang mewakili suatu keadaan atau kondisi tertentu dalam suatu variabel fuzzy.

\section{Contoh : Variabel Permintaan Konsumen}

Bentuk grafis fungsi keanggotaan linear turun, segitiga, dan linear naik untuk Variabel Permintaan Konsumen seperti terlihat pada gambar 1.

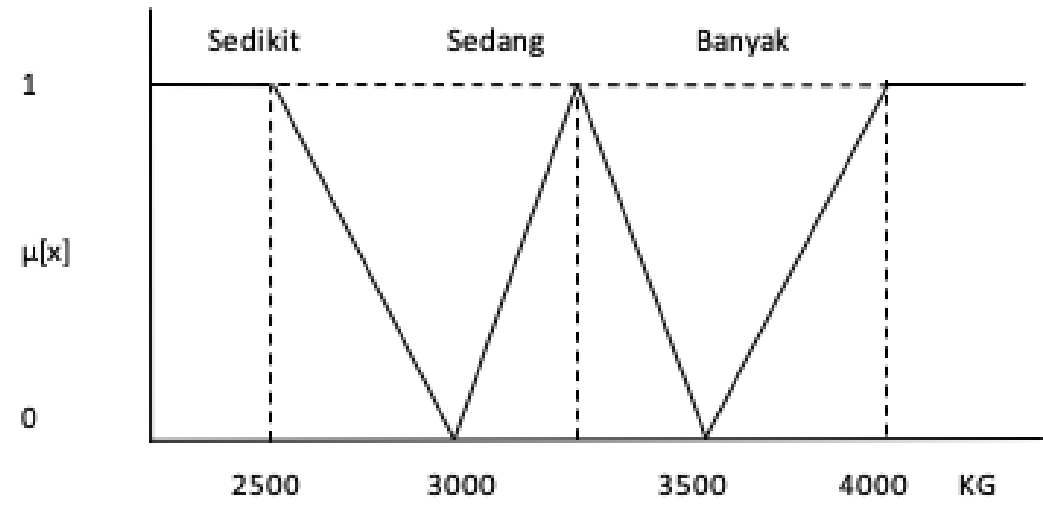

\section{Gambar 1. Grafik Fungsi keanggotaan Linear Turun, Segitiga, dan Linear Naik Untuk Variabel Permintaan Konsumen}

3. Rule Base

1. If permintaan_konsumen sedikit and persediaan sedikit and bahan sedikit and bahan_baku sedikit then produksi berkurang.

2. If permintaan_konsumen sedikit and persediaan sedikit and bahan sedikit and bahan_baku sedang then produksi tetap. 
3. If permintaan_konsumen sedikit and persediaan sedikit and bahan sedikit and bahan_baku banyak then produksi bertambah.

4. If permintaan_konsumen sedikit and persediaan sedang and bahan sedikit and bahan_baku sedikit then produksi berkurang.

5. If permintaan_konsumen sedikit and persediaan sedang and bahan sedikit and bahan_baku sedang then produksi tetap.

6. If permintaan_konsumen sedikit and persediaan sedang and bahan sedikit and bahan_baku banyak then produksi bertambah.

7. If permintaan_konsumen sedikit and persediaan banyak and bahan sedikt and bahan_baku sedikit then produksi berkurang.

8. If permintaan_konsumen sedikit and persediaan banyak and bahan sedikit and bahan_baku sedang then produksi tetap.

9. If permintaan_konsumen sedikit and persediaan banyak and bahan sedikit and bahan_baku banyak then produksi bertambah.

10. If permintaan_konsumen sedang and persediaan sedikit and bahan sedikit and bahan_baku sedikit then produksi berkurang.

11. If permintaan_konsumen sedang and persediaan sedikit and bahan sedikit and bahan_baku sedang then produksi tetap.

12. If permintaan_konsumen sedang and persediaan sedikit and bahan sedikit and bahan_baku banyak then produksi bertambah.

13. If permintaan_konsumen sedang and persediaan sedang and bahan sedikit and bahan_baku sedikit then produksi berkurang.

14. If permintaan_konsumen sedang and persediaan sedang and bahan sedikit and bahan_baku sedang then produksi tetap.

15. If permintaan_konsumen sedang and persediaan sedang and bahan sedikit and bahan_baku banyak then produksi bertambah.

16. If permintaan_konsumen sedang and persediaan banyak and bahan sedikit and bahan_baku sedikit then produksi berkurang.

17. If permintaan_konsumen sedang and persediaan banyak and bahan sedikit and bahan_baku sedang then produksi tetap.

18. If permintaan_konsumen sedang and persediaan banyak and bahan sedikit and bahan_baku banyak then produksi bertambah.

19. If permintaan_konsumen banyak and persediaan sedikit and bahan sedikit and bahan_baku sedikit then produksi berkurang.

20. If permintaan_konsumen banyak and persediaan sedikit and bahan sedikit and bahan_baku sedang then produksi tetap.

21. If permintaan_konsumen banyak and persediaan sedikit and bahan sedikit and bahan_baku banyak then produksi bertambah.

22. If permintaan_konsumen banyak and persediaan sedang and bahan sedikit and bahan_baku sedikit then produksi berkurang.

23. If permintaan_konsumen banyak and persediaan sedang and bahan sedikit and bahan_baku sedang then produksi tetap.

24. If permintaan_konsumen banyak and persediaan sedang and bahan sedikit and bahan_baku banyak then produksi bertambah.

25. If permintaan_konsumen banyak and persediaan banyak and bahan sedikit and bahan_baku sedikit then produksi berkurang. 
26. If permintaan_konsumen banyak and persediaan banyak and bahan sedikit and bahan_baku sedang then produksi tetap.

27. If permintaan_konsumen banyak and persediaan banyak and bahan sedikit and bahan_baku banyak then produksi bertambah.

\section{Flowchart Fuzzy Mamdani}

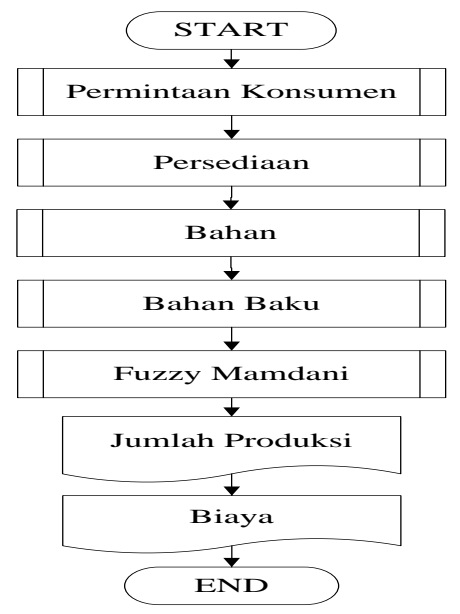

Gambar 2. Flowchart Penalaran Fuzzy Mamdani

\section{Procedure Variabel Permintaan Konsumen}

Berikut ini adalah procedure variabel permintaan konsumen untuk menentukan input berdasarkan himpunan fuzzy Sedikit, Sedang, dan Banyak pada Gambar 3.

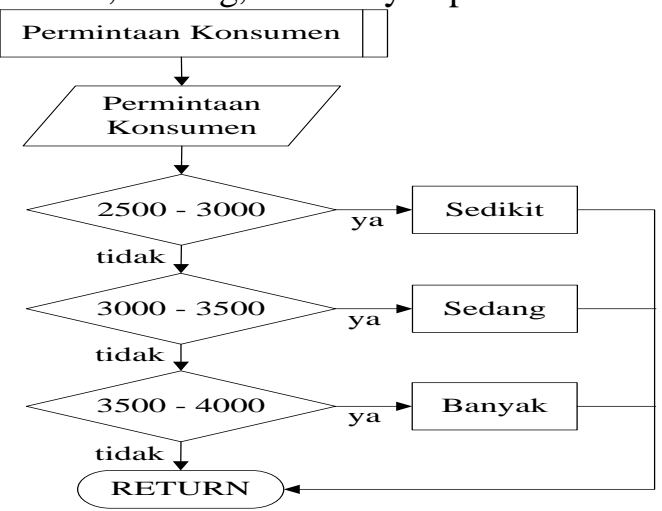

\section{Gambar 3. Procedure Variabel Permintaan Konsumen}

\section{Prosedure Fuzzy Mamdani}

Berikut ini procedure fuzzy mamdani untuk menentukan output pada Gambar 4.

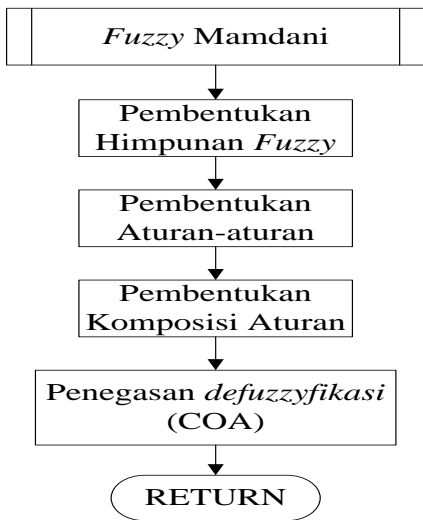

Gambar 4. Procedure Fuzzy Mamdani 


\section{Hasil dan Pembahasan}

\subsection{Form Proses}

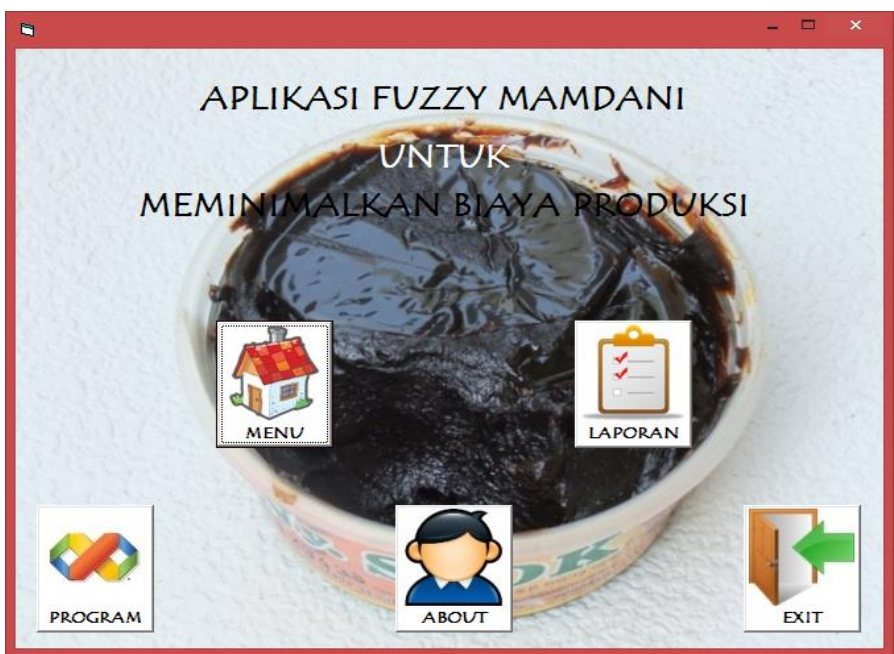

Gambar 5. Form Utama

\subsection{Form Proses}

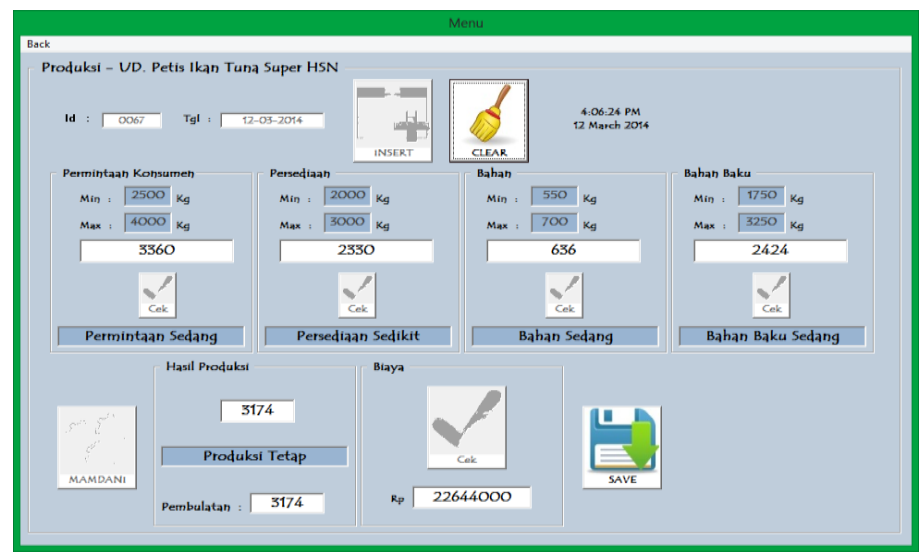

Gambar 6. Form Proses

\subsection{Form Report}

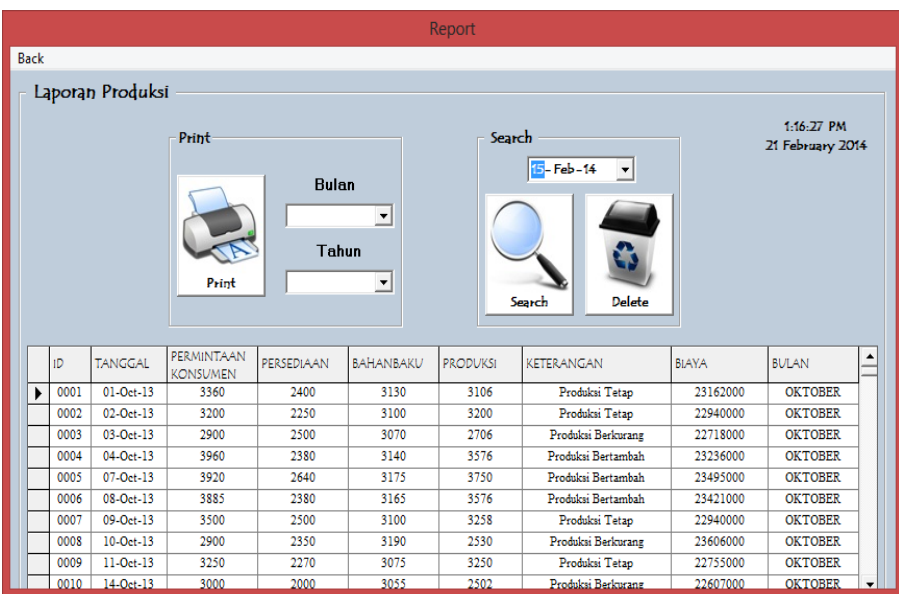

Gambar 7. Form Report 
Tabel 3. Hasil Uji Coba Perbandingan Jumlah Produksi

\begin{tabular}{|c|c|c|c|c|c|c|}
\hline TANGGAL & PERMINTAAN & PERSEDIAAN & $\begin{array}{c}\text { BAHAN } \\
\text { BAKU }\end{array}$ & $\begin{array}{c}\text { PRODUKSI } \\
\text { UD. Petis } \\
\text { Ikan Tuna } \\
\end{array}$ & $\begin{array}{c}\text { PRODUKSI } \\
F U Z Z Y \\
\text { MAMDANI }\end{array}$ & AKURASI \\
\hline 01-Oct-17 & 3360 & 2400 & 3130 & 3118 & 3106 & $99,61 \%$ \\
\hline 02-Oct-17 & 3200 & 2250 & 3100 & 3150 & 3200 & $98,43 \%$ \\
\hline 03-Oct-17 & 2900 & 2500 & 3070 & 2708 & 2706 & $99,92 \%$ \\
\hline 04-Oct-17 & 3960 & 2380 & 3140 & 3358 & 3576 & $93,90 \%$ \\
\hline 07-Oct-17 & 3920 & 2640 & 3175 & 3462 & 3750 & $92,93 \%$ \\
\hline 08-Oct-17 & 3885 & 2380 & 3165 & 3370 & 3576 & $94,23 \%$ \\
\hline 09-Oct-17 & 3500 & 2500 & 3100 & 3179 & 3258 & $97,57 \%$ \\
\hline 10-Oct-17 & 2900 & 2350 & 3190 & 2860 & 2530 & $88,46 \%$ \\
\hline 11-Oct-17 & 3250 & 2270 & 3075 & 3162 & 3250 & $97,29 \%$ \\
\hline 14-Oct-17 & 3000 & 2000 & 3055 & 2778 & 2502 & $90,06 \%$ \\
\hline 15-Oct-17 & 3500 & 2500 & 3070 & 3138 & 3206 & $97,87 \%$ \\
\hline 16-Oct-17 & 3260 & 2240 & 3180 & 3220 & 3260 & $98,77 \%$ \\
\hline 17-Oct-17 & 2830 & 2750 & 3100 & 2866 & 2632 & $91,83 \%$ \\
\hline 18-Oct-17 & 2750 & 2170 & 3130 & 2940 & 2750 & $93,53 \%$ \\
\hline 21-Oct-17 & 3160 & 2735 & 3095 & 3102 & 3110 & $99,74 \%$ \\
\hline 22-Oct-17 & 3360 & 2500 & 3120 & 3160 & 3200 & $98,75 \%$ \\
\hline 23-Oct-17 & 3725 & 2965 & 3105 & 3077 & 3050 & $99,12 \%$ \\
\hline 24-Oct-17 & 3850 & 2830 & 3190 & 3470 & 3750 & $92,53 \%$ \\
\hline 25-Oct-17 & 2500 & 2000 & 3155 & 2828 & 2501 & $88,43 \%$ \\
\hline 28-Oct-17 & 3520 & 2100 & 3175 & 3347 & 3520 & $95,08 \%$ \\
\hline 29-Oct-17 & 3405 & 2060 & 3130 & 3111 & 3092 & $99,38 \%$ \\
\hline 30-Oct-17 & 2955 & 2270 & 3125 & 2937 & 2750 & $93,63 \%$ \\
\hline 31-Oct-17 & 3050 & 2645 & 3105 & 3077 & 3050 & $99,12 \%$ \\
\hline
\end{tabular}

Maka dapat disimpulkan bahwa uji coba dengan menggunakan sistem fuzzy mamdani tingkat akurasi mencapai $95,66 \%$ per bulan.

$$
\text { Rata }- \text { rata Akurasi }=\frac{\text { Total jumlah akurasi }}{\text { Banyak jumlah Akurasi }}=\frac{2200,18 \%}{23}=95,66 \%
$$

\section{Kesimpulan}

Dari uraian-uraian, maka dapat diambil kesimpulan tentang Aplikasi fuzzy mamdani untuk meminimalkan biaya produksi petis sebagai berikut:

1. Dengan menggunakan sistem ini, dapat mencapai tingkat akurasi sebesar $95,66 \%$ per bulan.

2. Dengan menggunakan sistem ini, dapat meminimalkan biaya produksi sebesar $5,15 \%$ per bulan.

Dengan demikian aplikasi ini bisa menjadikan aplikasi yang efektif dan membantu pemilik perusahaan dalam proses produksi.

\section{Referensi}

[1] E. Turban, E. Jay, and T. Liang, "Decision Support System and Intelligent System-7th Ed (Sistem Pendukung Keputusan dan Sistem Cerdas Jilid 1)," Andi Offset, Yogyakarta, hal, pp. 143-144, 2005.

[2] H. Purnomo and S. Kusumadewi, "Aplikasi logika Fuzzy untuk pendukung keputusan," Yogyakarta: Graha Ilmu, 2010.

[3] D. Kusuma, "Artificial Intelligence Teknik dan Aplikasinya," Graha Ilmu, Yogyakarta, 2003.

[4] S. Kusumadewi and I. Guswaludin, "Fuzzy Multi-Criteria Decision Making," Media Informatika, vol. 3, no. 1, 2005.

[5] Y. Chai, L. Jia, and Z. Zhang, "Mamdani model based adaptive neural fuzzy inference system and its application," International Journal of Computational Intelligence, vol. 5, no. 1, pp. 22 29, 2009. 